\title{
COVID-19 and the Future of the Annual Meeting
}

Dylan Ruediger

Danielle Cooper 


\section{ITHAKA S+R}

Ithaka $\mathrm{S}+\mathrm{R}$ provides research and strategic guidance to help the academic and cultural communities serve the public good and navigate economic, demographic, and technological change. Ithaka $\mathrm{S}+\mathrm{R}$ is part of ITHAKA, a not-for-profit with a mission to improve access to knowledge and education for people around the world. We believe education is key to the wellbeing of individuals and society, and we work to make it more effective and affordable.

Copyright 2021 ITHAKA. This work is licensed under a Creative Commons Attribution 4.0 International License. To view a copy of the license, please see https://creativecommons.org/licenses/by/4.0/.

ITHAKA is interested in disseminating this brief as widely as possible. Please contact us with any questions about using the report: research@ithaka.org. 


\section{Introduction}

In February 2020, the Biogen conference in Boston, Massachusetts, became one of the first superspreader events in the United States-one now linked to perhaps 300,000 cases of COVID19. ${ }^{1}$ By mid-March, in-person conferences, a staple of scholarly communication and community, came to an abrupt halt. For the many professional societies for whom a conference is a core offering, the necessity of charting a new path for their annual meeting was among the most difficult organizational challenges created by the pandemic. As one meeting director noted, the experience was "like flying an airplane while you're building it." ${ }^{2}$ The experiments of 2020-21 were born of necessity but aligned to pressures that had been building for years.

For a brief moment this spring, it was perhaps tempting to assume that the pandemic was behind us, and that conferences could and would quickly return to "normal." The Delta variant has made it clear that there is no clear path back to the pre-pandemic society meeting and has forced another round of cancellations and format shifts for conferences originally planned as inperson events. Given the ongoing uncertainty in global, national, and local, public health situations, conference organizers must reckon with the successes and failures of recent experiments with conference modalities. Much has already been learned, but important questions, ranging from identifying sustainable financial models to support new and mixed meeting formats and how those formats might engage new audiences in new forms of scholarly communication, remain unanswered. What does seem clear is that even after the pandemic recedes, many conferences and other types of scholarly meetings and programming are unlikely to simply return to the old status quo. ${ }^{3}$

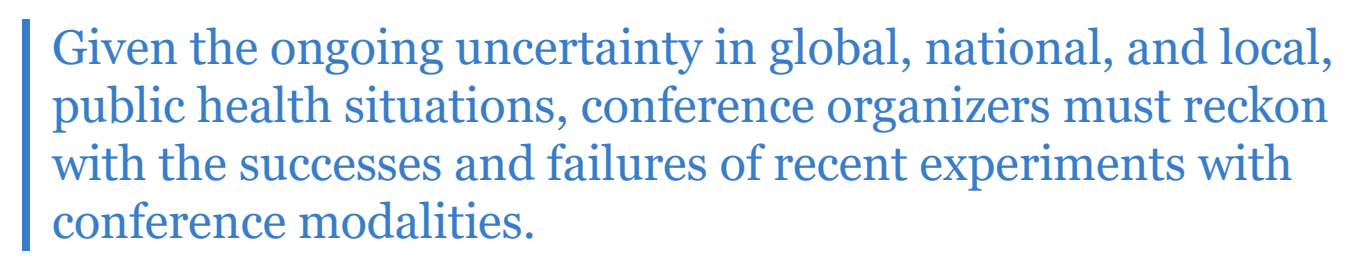

With generous funding from the Alfred P. Sloan Foundation, Ithaka S+R and JSTOR Labs will soon organize a cohort of scholarly societies to explore and develop the future of the scholarly meeting - through traditional, hybrid, and fully online modes for annual meetings, regional conferences, webinars, and professional education programs. ${ }^{4}$ Through a combination of

\footnotetext{
${ }^{1}$ Michael Wines and Amy Harmon, "What Happens When a Superspreader Event Keeps Spreading," The New York Times, December 12, 2020, https://www.nytimes.com/2020/12/11/us/biogen-conference-covid-spread.html; Farah Stockman and Kim Barker, "How a Premier U.S. Drug Company Became a Virus 'Super Spreader," The New York Times, April 12, 2020, https://www.nytimes.com/2020/04/12/us/coronavirus-biogen-boston-superspreader.html.

${ }^{2}$ Ariana Remmel, "Scientists Want Virtual Meetings to Stay after the COVID Pandemic," Nature, March 2, 2021, https://doi.org/10.1038/d41586-021-00513-1.

${ }^{3}$ Amy J. Ko, "On the Future of Academic Conferences," Medium, July 24, 2020, https://medium.com/bits-and-behavior/on-thefuture-of-academic-conferences-c0a54f027423; Grace Liu, "The Surprising Advantages of Virtual Conferences," Scientific American, August 21, 2020, https://www.scientificamerican.com/article/the-surprising-advantages-of-virtual-conferences/; Michael Price, "Scientists Discover Upsides of Virtual Meetings," Science 368, no. 6490 (2020): 457-58.

${ }^{4}$ Danielle Cooper and Dylan Ruediger, "The Future of Scholarly Meetings: Announcing a New Cohort Project Funded by the Sloan Foundation," Ithaka S+R, October 18, 2021, https://sr.ithaka.org/blog/the-future-of-scholarly-meetings.
} 
primary research, collaboration, and design thinking, this cohort will work together to address the business, content, and membership challenges societies face as they develop long-term planning for multi-modal conferences.

As we embark on that new project to explore what the turn to virtual conferences will mean for societies' strategic planning in the years to come, it is important to take stock of the immediate past. The outbreak of the pandemic left societies with little choice except to embrace virtual meetings, forcing experimentation at a scale that was previously unthinkable. Though produced by a crisis, the virtual experiments raise fundamental questions about the purpose and function of future annual meetings. Did the pandemic accelerate a set of innovations that were already desperately needed? Or did it introduce an entirely new set of needs and opportunities? These are particularly urgent questions for societies that had already seen steady declines in annual meeting attendance in the years prior to the pandemic: for many professional societies in the humanities, for example, it would be an enormous mistake to try to return to the status quo ante.

Regardless of disciplinary affiliation, societies are now assessing how virtual or hybrid annual meetings might provide opportunities to re-imagine the genre, its conventions, and the shape of academic communities. While individual societies made unique decisions based on their resources, members' needs, and organizational goals, there is value in a wider ranging exploration of how societies adjusted to the necessities of the pandemic, which will aid decision makers assessing future directions for their annual meetings.

To assist in this assessment, we've taken a deep dive into trends in the changes scholarly societies made to annual meetings scheduled between March 2020 to September 2021. Three key questions, one descriptive, one analytic, and one speculative, guide our analysis:

- How have societies adapted their annual meetings in the face of the pandemic?

- What lessons about the future of annual meetings can we learn from their experiences doing so?

- What questions and topics should guide future research aimed at supporting these important forms of scholarly communication?

Understanding the choices that societies made in light of the pandemic can tell us about annual meetings in the years to come and clarify what further evidence societies will need as they make critical choices about the future of one of their most intellectually and financially important offerings.

\section{The Uncertain Futures of Academic Conferences Before COVID}

The future of the conference is such a pressing concern because annual meetings are central to the mission of many societies: they provide important forums for exercising societies' power to convene, to influence research, and intervene in pedagogical and professional issues within disciplines and disciplinary communities. They are also often major financial investments (regardless of whether they are designed to generate net revenue or simply recoup costs) with 
considerable collateral impacts on other revenue categories such as membership, since presenters and attendees are incentivized to become members. ${ }^{5}$ Annual meetings are often the site of important governance functions including business, caucus, and board meetings. They are also opportunities to gather feedback and ideas from members and identify future leadership. Perhaps most importantly, annual meetings are concrete manifestations of the disciplinary and membership communities that societies serve, places where scholars gather in large numbers and across subfields. The combination of these functions distinguishes annual meetings from other types of conferences. In theory at least, annual meetings offer the chance for entire disciplines and fields of inquiry to gather in ways that run counter to the hyperspecialization that characterizes much of academic life.

Yet, in recent years, scholarly societies have faced pressure to fundamentally change familiar aspects of their annual meetings. Critics have suggested that conferences too often rely on outmoded and ineffective means of scholarly communication. ${ }^{6}$ The high cost of attendance is a substantial burden to graduate students, early-career scholars, independent scholars, and to many contingent and tenure-track faculty. Accounts of cultural problems associated with annual meetings, ranging from high stress and sometimes inappropriate job interviewing practices, ${ }^{7}$ drinking cultures, ${ }^{8}$ and stories of sexual and other forms of harassment, are commonplace. ${ }^{9}$ Environmentally oriented fields in particular have wrestled with the carbon footprints of inperson meetings. ${ }^{10}$

\section{Prior to the pandemic, calls for experimentation with virtual
annual meetings were largely aspirational.}

Even before COVID-19, these and other factors were creating serious calls for reforming annual meetings. A greater willingness to hold virtual meetings were among the remedies that critics suggested, particularly for problems related to cost to participants, inclusivity, and climate

\footnotetext{
${ }^{5}$ For an overview of conference costs and business models, see Mark Carden, "What Should A Conference Cost?" The Scholarly Kitchen, February 11, 2021, https://scholarlykitchen.sspnet.org/2021/02/11/guest-post-what-should-a-conference-cost/.

${ }^{6}$ Brian Lovett, "Science Conferences Are Stuck in the Dark Ages," Wired, January 3, 2020, https://www.wired.com/story/opinionscience-conferences-are-stuck-in-the-dark-ages/; Duncan Green, "Conference Rage: "How Did Awful Panel Discussions Become the Default Format?"' The Guardian, June 2, 2016, http://www.theguardian.com/global-development-professionalsnetwork/2016/jun/02/conference-rage-how-did-awful-panel-discussions-become-the-default-format; Mark Rom, "The Scholarly Conference: Do We Want Democracy and Markets or Authority and Tradition?" Journal of Political Science Education 8, no. 4 (October 2012): 333-51, https://doi.org/10.1080/15512169.2012.729449; Michelle D. Deardorff, "Reconsidering the Scholarly Conference for the Contemporary Academic," PS: Political Science and Politics 48, no. 2 (2015): 315-18.

${ }^{7}$ Colleen Flaherty, "Killing the Conference Interview," Inside Higher Ed, September 9, 2019, https://www.insidehighered.com/news/2019/09/09/economists-end-single-hotel-room-interviews-and-historians-end-conferenceinterviews.

${ }^{8}$ Allison Miller, "In Some Disciplines, Heavy Drinking Is Part of the Culture. That Can Be a Problem," Science, December 6, 2018, https://www.sciencemag.org/careers/2018/12/some-disciplines-heavy-drinking-part-culture-can-be-problem.

${ }^{9}$ Sara Custer, "Twitter Responses Show Sexual Harassment Is Rife at Academic Conferences," Times Higher Education, May 21, 2019, https://www.timeshighereducation.com/blog/twitter-responses-show-sexual-harassment-rife-academic-conferences.

${ }_{10}$ Alan MacEachern, "Well-Grounded," NiCHE, July 10, 2019, https://niche-canada.org/2019/07/10/a/; Peter Bickerton, "Is This the Future of Science Conferences? If We Are Serious about Climate Action, We Must Surely Go Virtual," Earlham Institute, December 4, 2020, https://www.earlham.ac.uk/articles/future-science-conferences-if-we-are-serious-about-climate-action-we-must-surely-govirtual; Abby Olena, "COVID-19 Ushers in the Future of Conferences," The Scientist, September 28, 2020, https://www.thescientist.com/news-opinion/covid-19-ushers-in-the-future-of-conferences-67978.
} 
change. To a limited, and sometimes unacknowledged degree, technological changes have already pushed some aspects of annual meetings into virtual spaces. Perhaps the most notable example of this is one of the most controversial features associated with many annual meetings-the first first-round job interviews that, in many disciplines, have defined the annual meeting for generations of academics. As first-round interviews have shifted to Zoom and other virtual formats, societies have stopped hosting them. Even so, it's fair to say that, prior to the pandemic, calls for experimentation with virtual annual meetings were largely aspirational. COVID-19 served as an unexpected, and tragic, catalyst for change.

\section{What Did 2020-21 Virtual Annual Meetings Look Like?}

To assess the landscape, we conducted desk research into COVID-affected 2020-21 annual meetings of 13 US-based professional societies. Our initial research was conducted in the spring of 2021 and then updated in September 2021 to reflect changes directly prompted by the spread of the Delta variant. Together, these two research phases help capture both initial responses to the pandemic and a sense of how societies have responded to ongoing and unpredictable shifts in the public health situation. Ithaka $\mathrm{S}+\mathrm{R}$ has considerable expertise in understanding the needs of scholars, gained through our triennial faculty survey and our research support services program, which has explored scholarly practices in a wide range of fields. ${ }^{11}$ To leverage that expertise, we focused on annual meetings held by major scholarly societies in fields that we have studied in detail, with a few additions designed to provide a rough balance between STEM, social/behavioral sciences, and humanities fields (see the Appendix for a list of societies included and links, when applicable, to our previous reports). We developed a brief rubric (detailed below) for conducting our analysis, which focused on a total of 19 annual meetings scheduled for between mid-March 2020 and the first of September 2021. Of these, six were canceled, and the remaining 13 were held virtually. Though small, this sample reflects a diversity of fields and provided an opportunity to test our instrument for future roll-out using a larger sample.

Our sample includes annual meetings for the following societies: the American Academy of Religion (AAR) and Society for Biblical Literature (SBL), the American Chemical Society (ACS), the American Historical Association (AHA), the American Political Science Association (APSA), the American Public Health Association (APHA), the American Society for Biochemistry and Molecular Biology (ASBMB) and Experimental Biology, the American Society of Civil Engineers (ASCE), the American Sociological Association (ASA), the Association for Asian Studies (AAS), the College Art Association (CAA), the Modern Language Association (MLA), the Native American and Indigenous Studies Association (NAISA), and the Tri-Societies (American Society of Agronomy, Crop Science Society of America, and Soil Science Society of America). Many of these organizations host meetings other than their annual meeting, and one (ACS) hosts two

\footnotetext{
${ }^{11}$ See "Research Support Services" on Ithaka S+R's website, https://sr.ithaka.org/our-work/research-support/, and the Appendix for a list of relevant reports on the research practices of faculty. See also Melissa Blankstein and Christine Wolff-Eisenberg, "Ithaka S+R US Faculty Survey 2018," Ithaka S+R, April 12, 2019, https://doi.org/10.18665/sr.311199.
} 
annual meetings each year. For this research project, only annual meetings were considered in scope. Dylan Ruediger, one of the authors of this report, recently worked for the American Historical Association, with job duties that included developing programming for their annual meeting and the Virtual AHA, which is discussed in more detail below.

We gathered the following information about 2020-21 virtual annual meetings:

- Was the meeting canceled or delayed? On what dates was the meeting held?

- What session formats and activity types were offered (e.g., research panels, posters, networking events, workshops, exhibit halls)

- Were sessions offered live, pre-recorded, or both?

- What platform(s) hosted the meeting?

- What were registration rates and attendance numbers, and how did those compare to inperson numbers from 2019-20?

- Finally, we explored the plans societies have announced for fall 2021 and early 2022 annual meetings in light of the continuing pandemic.

This study relied entirely on publicly available information, and the quality and type of information available varied from society to society. Thus, data collection for some fieldsincluding hosting platforms, the discount rate for registration, and attendance-were often difficult to discern. Attendance numbers, unfortunately, do not often circulate widely. Our data is indicative, rather than comprehensive, and better equipped to document outcomes than the processes behind the complex decisions that scholarly societies have been forced to make in the last year and a half. Nevertheless, it provides a jumping off point for further research and conversation. As Ithaka S+R's research in this area shifts towards extensive engagement with conference organizers and strategic planners at scholarly and professional societies, we are looking forward to sustained conversations about internal decision-making processes regarding annual meetings and other conferences.

\section{Cancellations}

Nearly half of the societies in our sample cancelled their 2020 annual meetings outright. Unsurprisingly, conferences scheduled for spring or summer were the most likely to be cancelled, starting with the 2020 Association for Asian Studies, scheduled to begin on March 19, 2020, and the American Chemical Society's spring annual meeting, scheduled for March 22-26, 2020. Delays were much less common: only one society pushed back its meeting dates, and even then, only by a couple of days.

However, the term "cancelled" is more complicated than it may initially sound and requires some parsing. In fact, only two annual meetings were outright cancelled. The Native American and Indigenous Studies Association, the smallest society in the sample, and the only one without paid staff, cancelled its 2020 annual meeting. So did one of the largest societies in our study, the ACS, which has 155,000 members and holds annual meetings in both spring and fall. The ACS canceled its spring 2020 meeting and appears to have focused its attention on preparing for its 
fall 2020 meeting, which was held in a virtual format. The AAS largely cancelled its meeting, but did broadcast a presidential address, an awards ceremony, and a virtual exhibit hall.

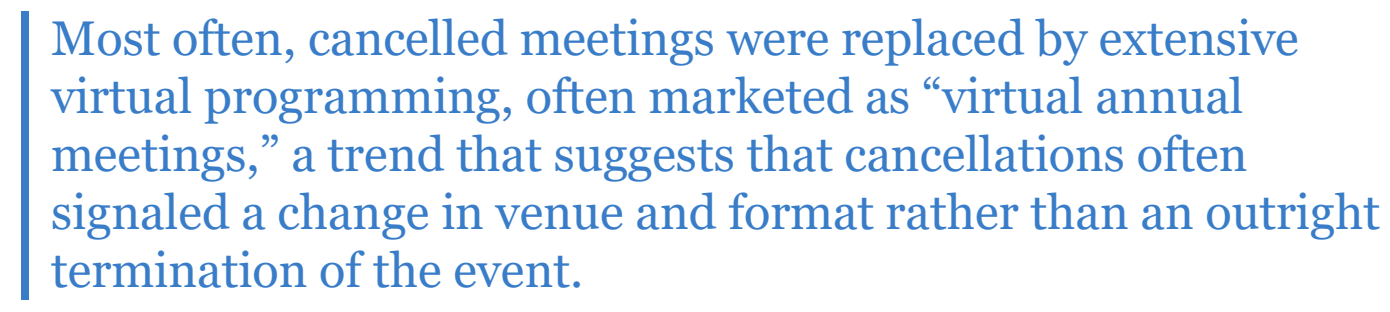

Most often, cancelled meetings were replaced by extensive virtual programming, often marketed as "virtual annual meetings," a trend that suggests that cancellations often signaled a change in venue and format rather than an outright termination of the event. The American Sociological Association, for example, has now cancelled its 2020 and 2021 annual meetings, replacing both with virtual annual meetings. The American Historical Association likewise canceled its 2021 meeting, opting to replace it with a "yearlong platform of online opportunities to bring together communities of historians." Though it replicates many of the familiar conference trappings: research panels (including many drawn from the 2021 AHA program), professional and career development workshops, networking events, and an exhibit hall, the organization insists that it is "not a virtual conference" but instead is a new kind of programming. ${ }^{12}$

The complex nomenclature around meeting cancellations suggests that societies adopted a range of marketing and communication strategies to inform their members about changes. Others may have been advised by counsel that, in order to invoke force majeure clauses in their meeting contracts, they would need to clearly cancel their annual meetings. In such cases, termination of the event may have been closely related to the need to terminate a contract. One clear avenue for further research would be to enumerate and better understand the financial and legal issues related to hotel contracts, organizational by-laws, and marketing strategies that affect the terminology different societies used to guide their planning. ${ }^{13}$ One laudable effect of the pandemic is that societies are beginning to communicate the financial costs of meetings to members as part of their communication around plans to proceed with or cancel in-person meetings. This spring, for instance, the American Academy of Religion communicated to its members that mounting a fully hybrid annual meeting would add $\$ 4.3$ million to its conference expenses. ${ }^{14}$ The significant costs associated with shifts in modality, which can include breaking contracts with hotels for room blocks and costs associated with streaming live events, are major

\footnotetext{
12 "Virtual AHA FAQ," American Historical Association, https://www.historians.org/virtualfaq.

${ }^{13}$ Roger C. Schonfeld and Laura Brown, "A Framework for the Future of Conferences," The Scholarly Kitchen, March 1, 2021, https://scholarlykitchen.sspnet.org/2021/03/01/framework-future-conferences/.

142021 Annual Meeting," American Academy of Religion, "https://www.aarweb.org/AARMBR/Events-and-Networking-/AnnualMeeting-/2021-Annual-Meeting.aspx. See also the less specific, but similar open letters from the Southern Historical Association https://www.thesha.org/assets/docs/SHA NO Letter.pdf and the Western History Association,

https://www.westernhistory.org/news/11101585. The latter was a response to calls from WHA members to cancel a meeting scheduled for San Antonio after passage of Texas Senate Bill 8.
} 
challenges confronting societies and will feature prominently in the upcoming Ithaka S+R and JSTOR Labs project on the future of scholarly meetings.

\section{Platforms}

We were able to determine information about the platforms that eight different societies used to host virtual annual meeting events: seven of them relied on Zoom for at least some session formats. This finding is in line with previous reporting from Ithaka $\mathrm{S}+\mathrm{R}$ staff that found heavy reliance on "basic webinar platforms," notably Zoom, for virtual conferences. ${ }^{15}$

Other vendors mentioned by name included Confex, EventScribe Live, Facebook Live, BAV Systems, and EventPilot (a web app that integrated with Zoom). YouTube, and videos embedded within conference program apps, were among the platforms used to archive content after initial broadcast. We saw little to suggest widespread use among societies of more "gamified" or VR/AR-based platforms such as Virtway, GatherTown, or SpatialChat. ${ }^{16}$

One obvious advantage of creating formal spaces for conversations among scholarly societies, such as those afforded by our upcoming future of scholarly meetings project, will be the opportunity to discuss the pros and cons of these platforms, a topic on which our research sheds little light. There is, however, an emerging literature on this topic, with particularly useful resources being developed by the Association for Computing Machinery's Task Force on Virtual Conferences, including an extensive, open-access, review of available platforms and software. ${ }^{17}$

\section{Registration}

Information about registration rates for either the 2020 or upcoming 2021 virtual meetings was gathered for nine societies. Of these, eight charged sliding scale rates depending on membership status and income or career stage, with regular member rates that ranged from $\$ 99$ to $\$ 325$. Five societies specifically mentioned that they had reduced registration rates for their virtual meetings relative to the previous year. Determining the rate of these discounts proved somewhat difficult. The American Political Science Association provided discounts of around 50 percent. The Association for Asian Studies offered discounts of 25 percent to attendees, and the Modern Language Association discounted registration by approximately 36 percent. The American Sociological Association offered discounted rates but did not specify the amount. Finally, the American Historical Association was an outlier here, as in many other respects: unlike any other organization, it offered the entirety of its virtual AHA programming free of charge. We can only speculate as to why some societies reduced their registration rates for virtual annual meetings. Some may have used discounts as a way of encouraging attendance at events which did not have proven audiences, or as an implicit acknowledgement that the perceived value of the experience

\footnotetext{
${ }^{15}$ Roger C. Schonfeld and Laura Brown, "A Framework for the Future of Conferences," The Scholarly Kitchen, March 1, 2021, https://scholarlykitchen.sspnet.org/2021/03/01/framework-future-conferences/.

${ }^{16}$ On which, see Mark Carden, "What Should A Conference Cost?" The Scholarly Kitchen, February 11, 2021, https://scholarlykitchen.sspnet.org/2021/02/11/guest-post-what-should-a-conference-cost/.

17 "Tools for Virtual Conferences,"

https://docs.google.com/document/d/1LLLniPkf48CCZyG BNy1ylF2wXNIztgNEOnzNuMQmJc/edit.
} 
had been diminished by the change in format. Discounts might also reflect efforts to pass the reduced costs of completely virtual meetings along to their members.

\section{Attendance}

Among the most desirable metrics for understanding COVID-era virtual meetings are attendance and vendor participation, but few societies make that information public during or immediately following their events. Unfortunately, desk research has been largely inconclusive on this point, as few of the societies explored here have posted attendance data. The three fields about which we have data very tentatively suggest that humanities scholars may have reacted more positively to virtual conferences than those in STEM fields. Published accounts from the MLA, which has a strong culture of transparency around attendance, suggest registration numbers roughly in line with attendance from recent conventions. ${ }^{18}$ Registration for the 2021 meeting of the Association for Asian Studies increased by four percent compared to its 2019 meeting, while the 2020 virtual meeting of the College Art Association reportedly attracted only nine percent fewer attendees than normal. ${ }^{19}$ In contrast, the fall 2020 meeting of the American Chemical Society was a significantly smaller than normal affair. From 2015-19, the meeting averaged 11,465 attendees (including students): the virtual fall meeting got just over half of that number $(6,221)$. Exhibitors declined from an average of 1,133 to just 233 (a 79 percent decrease). Attendance at their hybrid fall meeting was slightly better, but still over 20 percent lower than their 2019 in-person fall meeting. ${ }^{20}$

Given the prevalence of the idea that virtual meetings are more accessible to early-career professionals, caregivers, and others who for financial, health, or other reasons find in-person participation at annual meetings difficult, ${ }^{21}$ it would be useful to know if the demographic composition and geographic distribution of attendees shifted along with the change to virtual formats. Likewise, many societies would likely want to know whether conference regulars continued to engage. Societies are presumably collecting this data for internal planning purposes, but publicly available information is scant and inconclusive. Graduate students comprised 25 percent of attendees at the 2021 MLA Convention, a figure the MLA called "on the

\footnotetext{
${ }^{18}$ Len Cassuto, "The Concrete Benefits of a Virtual Conference," Chronicle of Higher Education, February 11, 2021, https://www.chronicle.com/article/the-concrete-benefits-of-a-virtual-conference; "MLA Convention Statistics," https://www.mla.org/Convention/Convention-History/MLA-Convention-Statistics.

${ }^{19}$ Yelena Kalinsky, "Online Conferences, Intellectual Property, and the Changing Shape of Scholarly Communications," H-Net Book Channel, https://networks.h-net.org/node/1883/discussions/7468664/online-conferences-intellectual-property-and-changing-shape.

${ }^{20}$ Information in this paragraph about ACS registration is drawn from: "Registration Statistics," https://www.acs.org/content/acs/en/meetings/acs-meetings/exhibitors/registration-statistics.html.

${ }^{21}$ Joshua Kim, "Academic Conferences After the Pandemic," Inside Higher Ed, October 13, 2020, https://www.insidehighered.com/blogs/learning-innovation/academic-conferences-after-pandemic; Grace Liu, "The Surprising Advantages of Virtual Conferences," Scientific American, August 21, 2020, https://www.scientificamerican.com/article/the-surprisingadvantages-of-virtual-conferences/; Ariana Remmel, "Scientists Want Virtual Meetings to Stay after the COVID Pandemic," Nature, March 2, 2021, https://doi.org/10.1038/d41586-021-00513-1; Rebecca M. Calisi and Working Group of Mothers in Science, "How to Tackle the Childcare-Conference Conundrum," Proceedings of the National Academy of Sciences of the United States of America 115, no. 12 (2018): 2845-49.
} 
high side of our usual range." 22 ACS attendance statistics, the most detailed available among the societies explored here, show a similar pattern: students made up about a third of attendees at the 2020 fall annual meeting, a number little changed from the previous five meetings. ${ }^{23}$

Once again, the AHA is an important outlier. In place of its annual meeting, it has adopted a year-long series of free programming. The AHA's model is unique among the societies explored here both for its extended duration (discussed in more detail below) and because it is entirely free to members and nonmembers. In terms of audience, the AHA's decision to demonetize its conference has been wildly successful: between its launch in summer 2020 and December, over 16,000 people had attended sessions or viewed recordings of them, a huge number for a society which has attracted roughly a third of that number to recent in-person annual meetings. ${ }^{24}$

\section{Programming Formats}

In general, societies reproduced most elements of their in-person meetings. Indeed, many virtual offerings look very similar to "normal" conference programs. Common elements include:

- Research-oriented sessions. Research sessions, such as keynotes, research panels, and poster sessions, are the backbone of many in-person annual meetings, a core mode of scholarly communication, and an important mechanism for scholars looking to build CVs and develop research agendas. These kinds of sessions may also have been considered relatively easy to convert to online formats, as they are usually oriented more towards presentation than to interaction. Research panels were offered at nearly every virtual meeting explored here. The only exception is NAISA, which did not accept research panels for its 2021 virtual meeting, having judged them poorly suited to the conversational, relationship based, and dialogic virtual environment they hope to support and towards which the discipline is oriented. ${ }^{25}$ Their 2021 virtual annual meeting included only two types of formats: roundtable discussions and creative works. One area of experimentation with research panels has been the widespread adoption of making recordings available to conference registrants after an initial live broadcast and experimentation with using prerecorded presentations that by-pass the need for a live panel. Both of these issues are explored in greater detail below.

- Social and networking events. The social value of conferences has become widely recognized as a major part of their value proposition. Large annual meetings provide rich opportunities for community building and networking with important interpersonal and professional benefits. Recent literature has also stressed that the networking associated with

\footnotetext{
22 Len Cassuto, "The Concrete Benefits of a Virtual Conference," Chronicle of Higher Education, February 11, 2021, https://www.chronicle.com/article/the-concrete-benefits-of-a-virtual-conference.

${ }^{23}$ ACS spring 2021 attendance figures are incomplete but may indicate a larger percentage of students than attended the fall 2020 meeting.

${ }^{24}$ Emily Swafford and Sarah Jones Weicksel, "Confronting a Pandemic," Perspectives on History, February 16, 2021, https://www.historians.org/publications-and-directories/perspectives-on-history/march-2021/confronting-a-pandemic-the-ahasupports-historians-with-the-help-of-neh-cares.

${ }^{25}$ Danielle Cooper et al, "When Research is Relational: Supporting the Research Practices of Indigenous Studies Scholars," Ithaka S+R, April 11, 2019, https://sr.ithaka.org/publications/supporting-the-research-practices-of-indigenous-studies-scholars/.
} 
conferences is important to the research process as well, with measurable effects on the quality and quantity of scientific collaboration. ${ }^{26}$ Nearly every society explored here offered some types of networking activities at their virtual meetings. However, despite some encouraging reports about the value of the in-channel chat feature used by some organizations at research panels, ${ }^{27}$ this seems to be a particularly challenging conference event to translate into virtual environments, not least because so much conference socializing occurs during downtime and in stolen moments. Over the long run, it's a major question for assessing the future of online or hybrid annual meetings, given widespread presumptions that "solutions that do not place interpersonal interaction at the forefront will fail in the long run, as they will not meet the need that conferences currently address." 28

- Professional development activities. Often offered as workshops, mini-courses, or roundtables, professional development programming has gained prominence in many fields as career paths for PhDs have shifted, membership compositions have changed, and teaching has carved out greater space in annual meeting programs. Many of the societies included in the sample supported "tracks" of programming devoted to professional development.

- Exhibit halls. Another conference staple, exhibit halls-particularly at big annual meetings-attract large numbers of publishers and vendors and equally large crowds of attendees. Beyond their commercial functions as marketplaces and important sources of revenue for conference organizers, exhibit halls also play a role in scholarly communication by providing a forum for editors and potential authors to meet. Unsurprisingly, most of the societies in this study attempted to translate them to virtual formats. Like networking events, exhibit halls are informal spaces, heavily reliant on foot-traffic, and ill-suited to Zoom and similar platforms. Tactics for replicating them in virtual spaces have varied-some humanities association's virtual exhibit halls were primarily platforms for purchasing books at discounts, others have included videos from vendors and live-chat functions. It's unclear how to best assess the success of these exhibitions. Reporting on them is sparse, but suggests that, like those networking events, virtual exhibit halls are another place with considerable room for improvement. ${ }^{29}$

- Governance. Annual meetings have long served as hubs for society governance functions such business, board, caucus, and committee meetings. All of these were common elements at 2020-21 virtual meetings. In most cases, their exact format is difficult to determine, but our sense is that many were little modified by their transition to virtual platforms. Indeed,

\footnotetext{
${ }^{26}$ Abby Olena, "COVID-19 Ushers in the Future of Conferences," The Scientist, September 28, 2020, https://www.thescientist.com/news-opinion/covid-19-ushers-in-the-future-of-conferences-67978; Emily Sohn, "The Future of the Scientific Conference," Nature 564, no. 7736 (December 19, 2018): S80-82, https://doi.org/10.1038/d41586-018-07779-y.

${ }^{27}$ Len Cassuto, "The Concrete Benefits of a Virtual Conference," Chronicle of Higher Education, February 11, 2021, https://www.chronicle.com/article/the-concrete-benefits-of-a-virtual-conference.

${ }^{28}$ Lisa Mighetto, "The Trouble with Conferences Part 1," NiCHE, July 3, 2019, https://niche-canada.org/2019/07/03/the-trouble-withconferences-part-11.

${ }^{29}$ Ann Bingham, "Virtual Conference Exhibits from the Publisher's Point of View," https://networks.hnet.org/node/1883/discussions/6649197/virtual-conference-exhibits-publisher\%E2\%80\%99s-point-view; Hajni Selby, "Stepping into 2D: Moving the Publisher Exhibit Online," https://networks.h-net.org/node/1883/discussions/6616815/stepping-2d-moving-publisherexhibit-online.
} 
one clear lesson from the past year is that these types of meetings, in organizations of all types, can be easily transferred to virtual settings with little loss in efficacy.

\section{Temporal Experimentation}

Our landscape view of COVID-era virtual meetings suggests significant continuities with inperson meetings. Given all the unknowns conference planners faced, this seems reasonable enough. The pivot to virtual engagements required considerable creativity and labor from society staff, and the stresses of doing so on short notice during a global pandemic encouraged "good enough" planning in ways that will be familiar to instructors who made abrupt adaptations to online teaching. Underneath the surface, however, there were two areas of significant innovation: lengthening of schedules, in some cases well beyond the standard longweekend format, and experimentation with circulating recorded content in place of, or as a supplement to, live broadcast of events. Both practices have the potential to significantly change the familiar temporal experience of conferences as dense and clearly-bounded events to something more elastic and less-differentiated-spatially and temporally-from everyday life. They also raise questions about whether we may see conferences morph into something that more closely resembles a content stream, a trend that seems emergent.

Freed from the financial and logistical constraints of physical gatherings, societies found opportunities to inject breathing room into their conference schedules. Some of these efforts were modest: the Association for Asian Studies, for example, added a few days to its original inperson schedule. The American Chemical Society met from April 5 to April 30, 2021. This trend is apparent in upcoming hybrid meets as well: the joint meeting of the American Academy of Religion and Society for Biblical Literature will meet from November 29 to December 10, 2021. Some societies-the Modern Language Association and the College Art Association, for example, hewed more closely to their normal in-person timelines, holding meetings of three to four days. However, they also made recordings of sessions available to registrants for extended periods after the formal end of the conference-a practice that amounts, in many respects, to elongating the duration of a conference. Most societies in our sample made recordings of panels available for a finite period of time, usually around a month. In most cases, access to these recordings was restricted to conference attendees as an incentive for registration, though some societies offered selected materials freely to wider audiences. In at least one instance-the 2020 Tri-Societies meeting-much of the program is freely, and apparently permanently, available through their website.

Clearly, the opportunity to easily expand a conference schedule is one of the immediate advantages that the virtual meetings of 2020-21 afforded. Extending schedules reduced Zoom fatigue and, more importantly, allowed organizers to reduce the need for concurrent panels while concentrate programming in prime slots-eliminating or reducing the dreaded 8:00 am panels-and centralizing programming into times that are convenient across multiple time zones. In theory, spreading panels more widely also allowed for greater participation, giving members the opportunity to pop in and out of the meeting as their schedule allowed. Making sessions available on demand further allowed attendees the option of fitting a conference 
around their schedules instead of putting other responsibilities on hold for several days to attend a conference.

Among societies that experimented with scheduling options, none went quite so far as the American Historical Association, here as elsewhere an instructive outlier. The content of its virtual AHA, a mix of roundtables, networking events, workshops, and panels (some drawn from the program of the cancelled 2021 annual meeting), was fairly conventional, but remarkable for how far it pushed the temporality of conferences. Whereas the cancelled in-person meeting would have taken place over a long weekend, the virtual AHA ran for an entire year, with multiple sessions held weekly for its duration. The majority of those sessions were then made freely and perpetually available on the organization's YouTube channel.

Extending schedules and providing on-demand content unquestionably increase the accessibility of conference programming and have the potential to greatly increase their audiences, but raise important questions:

1. How do we value the conference as a discrete event? How far can a meeting be stretched before its identity becomes diluted beyond recognition? The experience of a conference has long been at least theoretically a collective one based on a shared experience in a liminal space: this is part of how conferences generate buzz and intellectual energy. Whether and how this experience can be maintained if meetings become weeks- or months-long events that attendees drop in and out of at their convenience is worth considering as societies balance the considerable conveniences that online formats can offer.

2. What are the implications of thinking about professional societies - which in many cases are oriented towards service to a discipline-as content providers and media organizations? The practice of making recordings of panels available has already attracted some controversy for both the intellectual property issues involved and concern that doing so fundamentally alters the communicative purpose of conference presentations: the transformation into media content may detract from, and even diminish, their value as places where scholars present provisional ideas and works in progress while seeking feedback from live audiences in transient, relatively safe, environments. ${ }^{30}$

\section{The Near-Term Future of Annual Meetings}

The immediate future of annual meetings remains up in the air. Even should the threat of COVID and the Delta variant recede, the fate of the university funds which subsidize that travel remains unknown. Public announcements about meetings scheduled for late 2021 and early 2022 reflect this uncertainty. Among the 13 societies in our sample, four are advertising inperson meetings (at least one of which includes "limited virtual programming") while eight are now explicitly planning for hybrid events. It seems quite possible that the in-person meetings

\footnotetext{
${ }^{30}$ Martha Buskirk, "How the College Art Association Bumbled Fair Use for Their Conference Presenters," Hyperallergic, February 18, 2021, https://hyperallergic.com/618356/how-the-college-art-association-bumbled-fair-use-for-their-conference-presenters/; Yelena Kalinsky, "Online Conferences, Intellectual Property, and the Changing Shape of Scholarly Communications," H-Net Book Channel, https://networks.h-net.org/node/1883/discussions/7468664/online-conferences-intellectual-property-and-changing-shape.
} 
may yet be forced to adopt some hybrid programming. Only one, the fall meeting of the American Society of Civil Engineers (scheduled for late October) has committed to a fully virtual meeting, a fact that might be read as indicating that the days of virtual annual meetings are over as soon as circumstances permit. Recent meeting practices also point towards the possibility that the future will include what are essentially parallel, rather than truly hybrid conferences, with smaller in-person meetings supplemented by distinct virtual ones with minimal access to live activities for virtual registrants. The potential for such meetings to exacerbate already pronounced inequalities of access to annual meetings is troubling.

Even so, the relative successes of virtual meetings have demonstrated a constituency for virtual events, and perhaps an expectation of them among the members of scholarly societies. Indeed,_a survey of Nature readers found that 74 percent believe scientific conferences should either remain virtual or adopt hybrid formats after the pandemic. ${ }^{31}$ Whether societies can build the financial, staffing, and technological frameworks for supporting virtual and hybrid meetings over the long haul remains to be determined, but the issues that initially pushed conversations towards virtual meetings will continue after the pandemic. And the pandemic has provided a largely, if not unilaterally, positive test of their viability.

\section{Areas for Future Inquiry}

Several key lessons will shape conversations about the future of academic conference.

1. Virtual programming will be an important part of the mission of scholarly societies in the future. The accessibility advantages virtual formats offer speak to the changing composition of member societies rooted in academic communities and resonate with organizational commitments to diversity and inclusion. Overall, panel presentations translated relatively well to virtual environments. However, issues relating to formatsuch as whether conference events should be recorded live or pre-recorded, and the implications of on-demand distribution-need to be considered in relation to the purpose and goals of scholarly communication, not just from technical or logistical, or even accessibility, perspectives.

2. In-person meetings will not disappear overnight. In-person meetings serve important interpersonal functions that have not yet proven fully replicable in virtual settings. The networking and social opportunities that annual meetings offer are valued by many members of scholarly communities. Even if societies wanted to do so, they would likely find it impossible to quickly abandon in-person meetings. The planning cycle for annual meetings of large societies is quite long: binding hotel contracts have been signed years in advance, which leave in-person events locked in place (and size) for years to come.

3. Regardless of format, organizing annual conferences is labor and capital intensive. Virtual programming may have certain efficiencies, but especially if it is treated as an additional new service, it will incur costs that societies will need to recoup.

\footnotetext{
${ }^{31}$ Ariana Remmel, "Scientists Want Virtual Meetings to Stay after the COVID Pandemic," Nature, March 2, 2021, https://doi.org/10.1038/d41586-021-00513-1.
} 
Hybrid meetings likewise have a host of financial challenges associated with streaming content from venues that may charge large premiums for these services.

4. Absent careful planning, new conference models may perpetuate structural inequalities and hierarchies of access. While virtual and hybrid conferences may reduce barriers to participation and mitigate the inequalities of access that are endemic in scholarly communities, the potential emergence of high status in-person meetings and parallel lower-status remote meetings may end up exacerbating rather than diminishing academic inequality.

5. Changes in modality provide opportunities for the emergence of new genres of scholarly communication. Even before the pandemic, societies were working to diversify the range of programming options they offer to members and develop new presentation formats. Virtual and hybrid formats provide an opportunity for even more experimentation and should include consideration of how to better align scholarly communication models with twenty-first century technologies and scholarly communities.

Annual meetings are deeply rooted parts of the scholarly landscape but have struggled to evolve in tandem with the communities they serve. The pandemic has revealed the possibility of significant change, which should invigorate questions about the relationships between format and purpose. As we look forward, we need to consider whether virtual, hybrid, and in-person meetings serve distinct, overlapping, or identical purposes, and for whom. What modality, or combination of modalities, best fit the needs of scholarly communities? What financial models can sustain them? How might new technologies and formats create opportunities for new types of scholarly communication? What are the risks and advantages of moving towards models that may increasingly resemble content streams? Are virtual formats delivering on their potential for diversifying attendees, or new barriers to just, equitable, and inclusive scholarly communities arising?

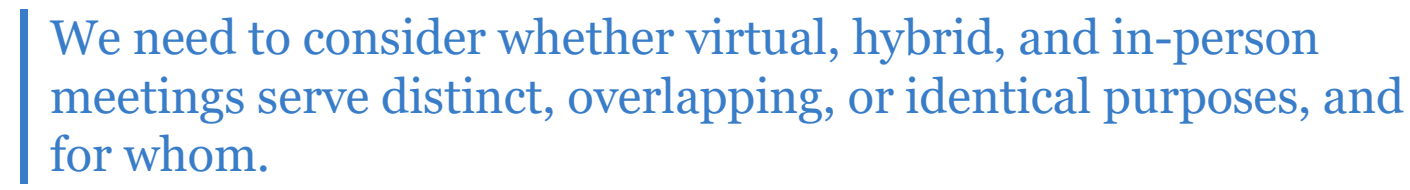

Different scholarly societies will develop distinct answers to these questions based on their missions, needs, and resources. But their decision-making would benefit from future research, including qualitative evaluations of the experiences of attendees and vendors, landscape assessments of existing and emerging platforms, and sustained conversations across disciplines about how to build on the lessons learned from the experiments of 2020-21. 


\section{Appendix: Societies Included in Study}

Society $\quad$ Broad Field(s) $\quad$ Previous Ithaka S+R Research Reports

\begin{tabular}{|c|c|c|}
\hline $\begin{array}{l}\text { American Academy of } \\
\text { Religion and Society for } \\
\text { Biblical Literature }\end{array}$ & Humanities & $\begin{array}{l}\text { Cooper, Danielle, Roger C. Schonfeld, et al. "Supporting the } \\
\text { Changing Research Practices of Religious Studies Scholars." Ithaka } \\
\text { S+R. Last Modified } 8 \text { February } 2017 . \\
\text { https://doi.org/10.18665/sr.294119. }\end{array}$ \\
\hline American Chemical Society & STEM & $\begin{array}{l}\text { Long, Matthew and Roger Schonfeld. "Supporting the Changing } \\
\text { Research Practices of Chemists." Ithaka S+R. Last Modified } 25 \\
\text { February 2013. https://doi.org/10.18665/sr.22561. }\end{array}$ \\
\hline $\begin{array}{l}\text { American Historical } \\
\text { Association }\end{array}$ & Humanities & $\begin{array}{l}\text { Rutner, Jennifer, and Roger C. Schonfeld. "Supporting the Changing } \\
\text { Research Practices of Historians." Ithaka S+R. Ithaka S+R. Last } \\
\text { Modified } 7 \text { December 2012. https://doi.org/10.18665/sr.22532. }\end{array}$ \\
\hline $\begin{array}{l}\text { American Political Science } \\
\text { Association }\end{array}$ & $\begin{array}{l}\text { Social and Behavioral } \\
\text { Sciences }\end{array}$ & \\
\hline $\begin{array}{l}\text { American Public Health } \\
\text { Association }\end{array}$ & STEM & $\begin{array}{l}\text { Cooper, Danielle, Katherine Daniel, et al. "Supporting the Changing } \\
\text { Research Practices of Public Health Scholars." Ithaka S+R. Last } \\
\text { Modified } 14 \text { December } 2017 \text {. https://doi.org/10.18665/sr.305867. }\end{array}$ \\
\hline $\begin{array}{l}\text { American Society for } \\
\text { Biochemistry and Molecular } \\
\text { Biology and Experimental } \\
\text { Biology }\end{array}$ & STEM & \\
\hline $\begin{array}{l}\text { American Society of Civil } \\
\text { Engineers }\end{array}$ & STEM & $\begin{array}{l}\text { Cooper, Danielle, Rebecca Springer, et al. "Supporting the } \\
\text { Changing Research Practices of Civil and Environmental } \\
\text { Engineering Scholars." Ithaka S+R. Last Modified } 16 \text { January } 2019 . \\
\text { https://doi.org/10.18665/sr.310885. }\end{array}$ \\
\hline
\end{tabular}

$\begin{array}{ll}\text { American Sociological } & \text { Social and Behavioral } \\ \text { Association } & \text { Sciences }\end{array}$
Association

Association for Asian Studies

Interdisciplinary
Cooper, Danielle, Katherine Daniel, et al. "Supporting the Changing Research Practices of Asian Studies Scholars." Ithaka S+R. Last Modified 21 June 2018. https://doi.org/10.18665/sr.307642.

$\begin{array}{ll}\text { College Art Association } \quad \text { Humanities } & \text { Schonfeld, Roger and Matthew Long. "Supporting the Changing } \\ & \text { Research Practices of Art Historians." Ithaka S+R. Last Modified } 30 \\ & \text { April 2014. https://doi.org/10.18665/sr.22833. }\end{array}$

Modern Language Humanities Association

Cooper, Danielle, Cate Mahoney, Rebecca Springer, et al. "Supporting Research in Languages and Literature." Ithaka S+R. Last Modified 9 September 2020. https://doi.org/10.18665/sr.313810.

Native American and
Indigenous Studies
Association
Tri-Societies (American
Society of Agronomy, Crop STEM
Science Society of America,
and Soil Science Society of
America)

Cooper, Danielle, et al. "When Research is Relational: Supporting the Research Practices of Indigenous Studies Scholars." Ithaka S+R. Last Modified 11 April 2019. https://doi.org/10.18665/sr.311240.

Cooper, Danielle, et al, "Supporting the Changing Research Practices of Agriculture Scholars," Ithaka S+R, Last Modified 7June 2017. https://doi.org/10.18665/sr.303663. 